\title{
ASYMMETRICAL HYPERTROPHY OF THE HEART IN YOUNG ADULTS
}

\author{
BY \\ DONALD TEARE \\ From the Department of Pathology, St. George's Hospital \\ Received January 7, 1957
}

"Tumours of the heart and pericardium have evoked an extensive literature out of all proportion to their uncommon incidence and their relative unimportance as a cause of clinical heart disease." This opening sentence of Friedberg's chapter on cardiac tumours in Diseases of the Heart (Friedberg, 1949) fills a pathologist with diffidence in reporting eight cases that have been seen in the last six years in a series of 16,000 autopsies.

Primary tumours of the heart are undoubtedly a rarity and according to Mahaim (1945) 413 had been recorded up to 1945 . There is little justification for recording rarities in young adults unless they have some relation to fitness for military service or confuse the differential diagnosis, particularly of conditions that may respond to cardiac surgery. These eight cases of asymmetrical hypertrophy or benign tumour of the heart have occurred in a large group where sudden death and indeed cardiac incapacity, particularly among men, is rare.

Primary tumours of the heart fall into three categories.

(1) Multiple tumours frequently described as congenital glycogenic tumours of the myocardium, which are often associated with other presumably congenital lesions such as tuberous sclerosis and renal tumours.

(2) Single diffuse tumours or asymmetrical hypertrophy of muscle and connective tissue, which are the subject of this article.

(3) Rare myxomata and sarcomata, occurring mainly in later life and producing a variety of symptoms and pathology.

Since the term rhabdomyoma is now firmly associated with nodular glycogenic tumours of the heart it is simpler to refer to the eight tumours under discussion as hamartomata, though they may in fact lay greater claim to being benign tumours of striped muscle than those of presumed glycogenic origin. In Mahaim's (1945) extensive review, which included 329 cases of primary tumour of the heart, only six are referred to as being diffuse tumours of the myocardium, and it would appear that the tumours discussed in this paper fall into this category.

Batchelor and Maun (1925) in recording one case of multiple tumours of the heart in a child of three days reviewed 62 other reported cases. In 60 cases the lesions were multiple, and of the three other cases, one was recorded as having hepatomegaly, one had congenital tumour of the lung, and one had no congenital abnormality. In Eulinger's (1925) record of 37 cases, seven were single tumours and no other congenital abnormality was found. Browne and Gray (1930) record a case of a child of three months who died following a fit of crying, and there was found a diffuse tumour of the lateral wall of the left ventricle similar to the cases about to be described. Hueper (1935 and 1941) described diffuse tumours in the heart of a negro and in the heart of a guinea-pig. Saphir (1953) used the term rhabdomyoma when writing of nodular glycogenic degeneration and gives no reference to benign tumours of striped muscle. Similarly Adams, Denny-Brown, and Pearson (1953) describe nodular glycogenic tumours when referring to rhabdomyoma of the heart. 


\section{CASE Histories}

Case 1. R. S. In September, 1950, a boy of 14, had had a "blackout" and fallen from his bicycle; two months later he again became dizzy and fell to the ground. In neither attack did he bite his tongue or pass water. He was seen at Wembley Hospital on January 1, 1951. At this time he was found to have a blood pressure of $118 / 70 \mathrm{~mm}$. $\mathrm{Hg}$, a third heart sound and a soft systolic murmur. There was no history of fits, rheumatic fever, or other significant background. He was advised to lead a normal life, excluding cycling, running, or climbing. It was thought that his attacks were cardiac in origin and not epileptic. On February 20, 1951, he was being chased around the playground of his school, when he suddenly collapsed and was found to be dead on arrival at hospital twenty minutes later.

His heart (Fig. 1) showed a localized and diffuse hypertrophy of the interventricular septum. The hypertrophied muscle had a coarse texture when compared with the lateral wall of the ventricle and the proximity of the hypertrophied area to the mitral valve is well seen in the photograph.

Microscopical examination of a section of the tumour (Fig. 2) shows a bizarre arrangement of bundles of muscle fibres running in divers directions and separated by connective tissue and clefts. The connective tissue tends to break up and interrupt the muscle bundles giving an impression of inefficiency in muscular contraction of the tumour as a whole, while the clefts are lined with endothelium covering sparse elastic tissue which is similar to the structure of the normal endocardium. The individual muscle fibres appear to be mature and there is no suggestion of malignancy; they vary considerably in thickness, but in any particular bundle the fibres are of the same thickness, and show sufficient nuclei to indicate that the fibres have been cut centrally and that the appearance of variation in thickness is not due to a chance tangential section.

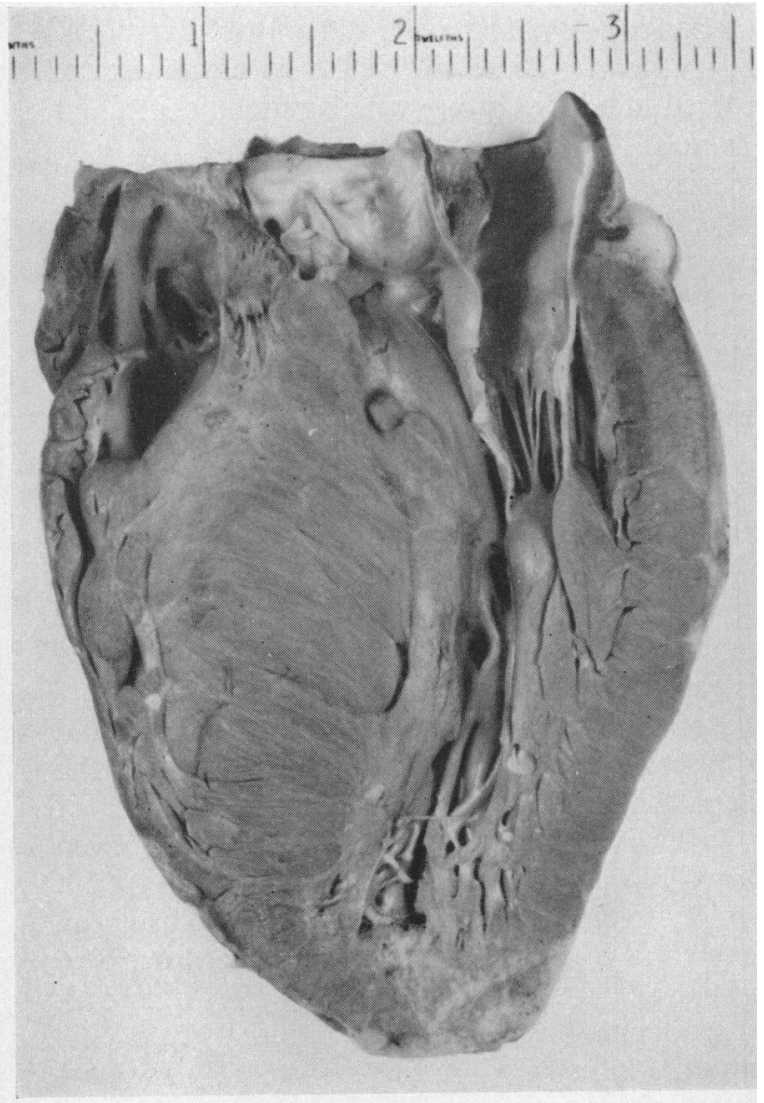

FIG. 1.-Case 1. Localized hypertrophy of the interventricular septum.

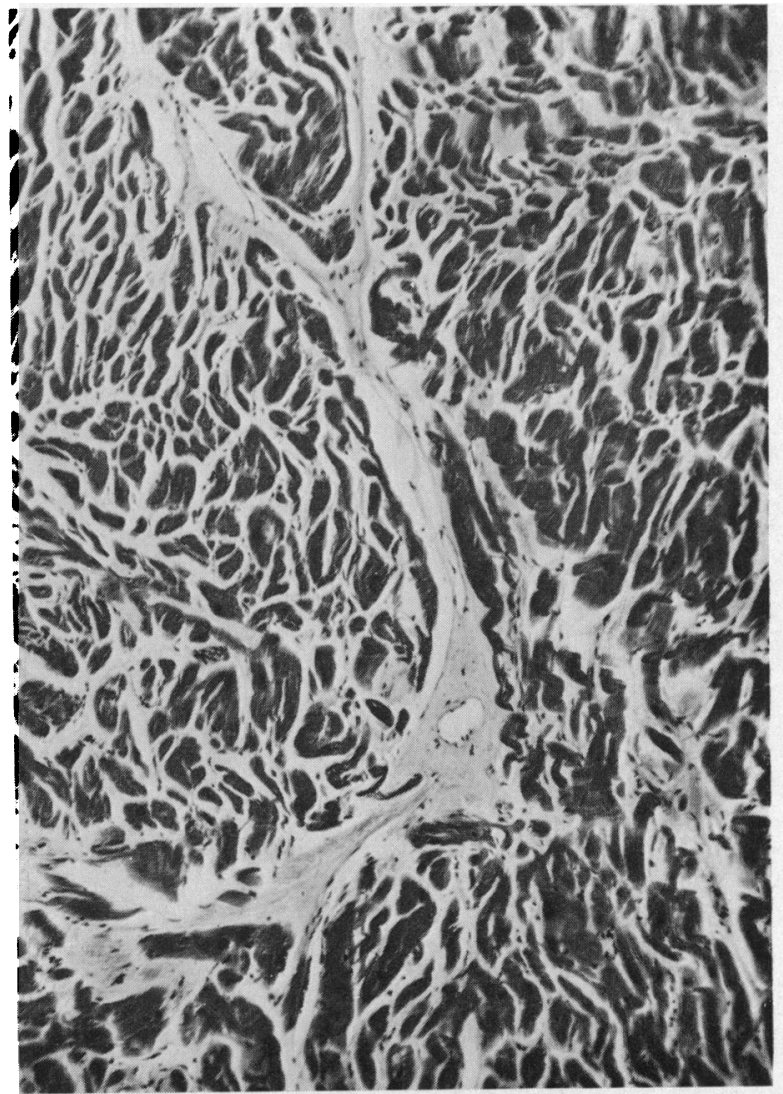

FIG. 2.-Case 1. Disordered arrangement of muscle bundles with variations in size of individual fibres $(H \& E \times 80)$. 
Case 2. E. C. B., aged 25. Apart from pneumonia and empyema when a child of six, this man had served in the Army and had been fit until the autumn of 1953 when he attended his general practitioner complaining of palpitation. No abnormality was detected on routine physical examination and he did not see his doctor again until November, 1954, when he was found to be in congestive heart failure with engorged neck veins, auricular fibrillation, and a pulse rate of 130 a minute. He refused to rest but agreed to take digoxin. Ten days later his pulse had fallen to $80 \mathrm{a}$ minute and the neck veins were less engorged. While walking home on December 26, 1954, he collapsed on the pavement and was found to be dead on reaching hospital twenty-five minutes later.

His heart (Fig. 3) showed hypertrophy similar to that seen in Case 1, though if anything the enlargement of the interventricular septum was greater. The same coarse texture of the muscle can be seen but there were no clefts. The microscopical picture was one of bizarre arrangement of muscle bundles and hypertrophy of individual muscle fibres.

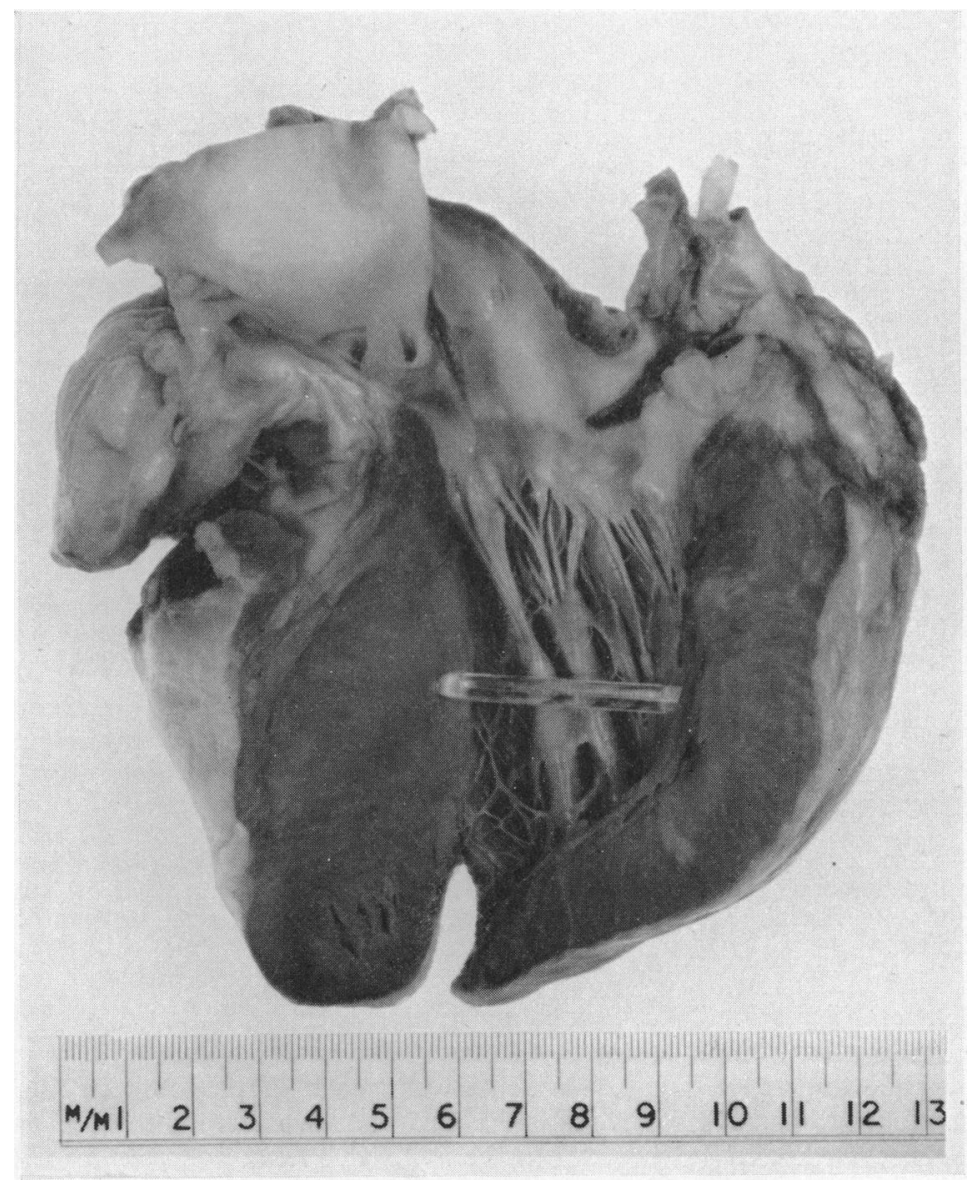

Fig 3.-Case 2. Hypertrophy of the interventricular septum with coarse texture of muscle.

Case 3. G. C., aged 25. This man first came under medical observation when he applied for employment at the Central Medical Establishment, R.A.F., in September, 1953. He claimed to be perfectly fit and free from symptoms. There was no history of rheumatic disease and he had always taken part in games without distress. His heart was in normal rhythm and his blood pressure 130/90. A soft highpitched systolic murmur just internal to the apex of the heart was heard. It was not accompanied by a thrill and no diastolic murmur was heard even after exercise. His electrocardiogram (Fig. 4) was grossly 
abnormal. He was thought to be fit for sedentary occupation, but not for establishment as a civil servant. He continued in his normal health until January 2, 1955, when he awoke from an afternoon sleep, had a series of fits, frothed at the mouth, became rigid, and was dead when a doctor arrived fifteen minutes later.

Post-mortem examination showed him to be well-nourished and muscular. His heart weighed $520 \mathrm{~g}$., this increase being due mainly to an asymmetrical hypertrophy of the interventricular septum and anterior wall of the heart. There was also some hypertrophy of the right atrium and ventricle. The bronchi contained a large quantity of frothy, slightly blood-stained, fluid, which appeared to have come from a terminal œdema of the lungs, and there was a small patch, 3 centimetres in diameter, of recent subarachnoid hæmorrhage over the left parietal cortex. No congenital lesions were found in any other organ.

The coarse and varied arrangement of muscle bundles are well seen in Fig. 5, and the clefts or fissures between muscle bundles were greater than in any other specimen. These endothelial-lined channels communicated with the cavities of both ventricles, but pursued such tortuous and muscle-bound courses as to suggest that there could be no shift of blood from one ventricle to another during systole. The histological picture was identical with the other cases.

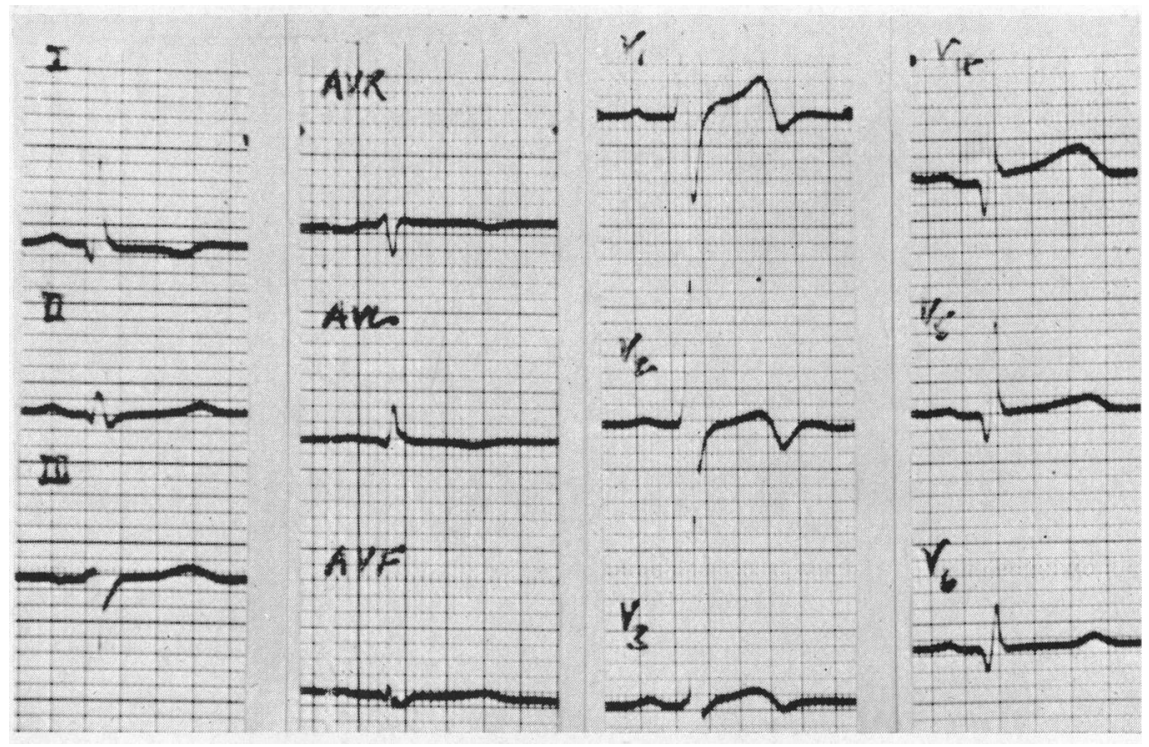

Fig. 4.-Case 3. $T$ inversion in lead $I$, terminal $T$ inversion in $V 1, V 2$, and $V 3$, and abnormally deep Q in V4, V5, and V6. These changes indicate areas of fibrosis or abnormally functioning myocardium in the anterior and lateral walls of the left ventricle.

Case 4. R. W., aged 45 years. This patient at the age of 28 complained of tiredness, pain in the chest, and dyspnœa on exertion. Her doctor at the time told her that she had a murmur and anæmia. These symptoms persisted and at the age of 40 she had an attack of palpitation, which necessitated her admission to hospital for cardiac irregularity where her symptoms responded to quinidine. At the age of 42 digitalization was necessary and valvotomy was considered. In the year prior to her death she had two attacks of breathlessness associated with the coughing up of bloodstained sputum. She slept with two pillows but could walk half a mile before being halted by dyspnœa. There was no history of rheumatic fever but many attacks of tonsillitis followed by scarlatina at the age of 13 .

On admission to Guy's Hospital on December 28, 1954, she was found to be fibrillating at the rate of 60 a minute, and her blood pressure was 150/85. At the apex a rumbling diastolic murmur with thrill was found, and a soft aortic diastolic murmur was also heard. Chest X-ray showed the heart to be of mitral shape and an electrocardiogram demonstrated auricular fibrillation with left ventricular preponderance. On January 2, 1955, auscultation r evealed a to-and-fro creaking sound, very like a friction rub, over the pulmonary area.

Operation for mitral valvotomy was undertaken on January 4; difficulty was encountered in introducing 


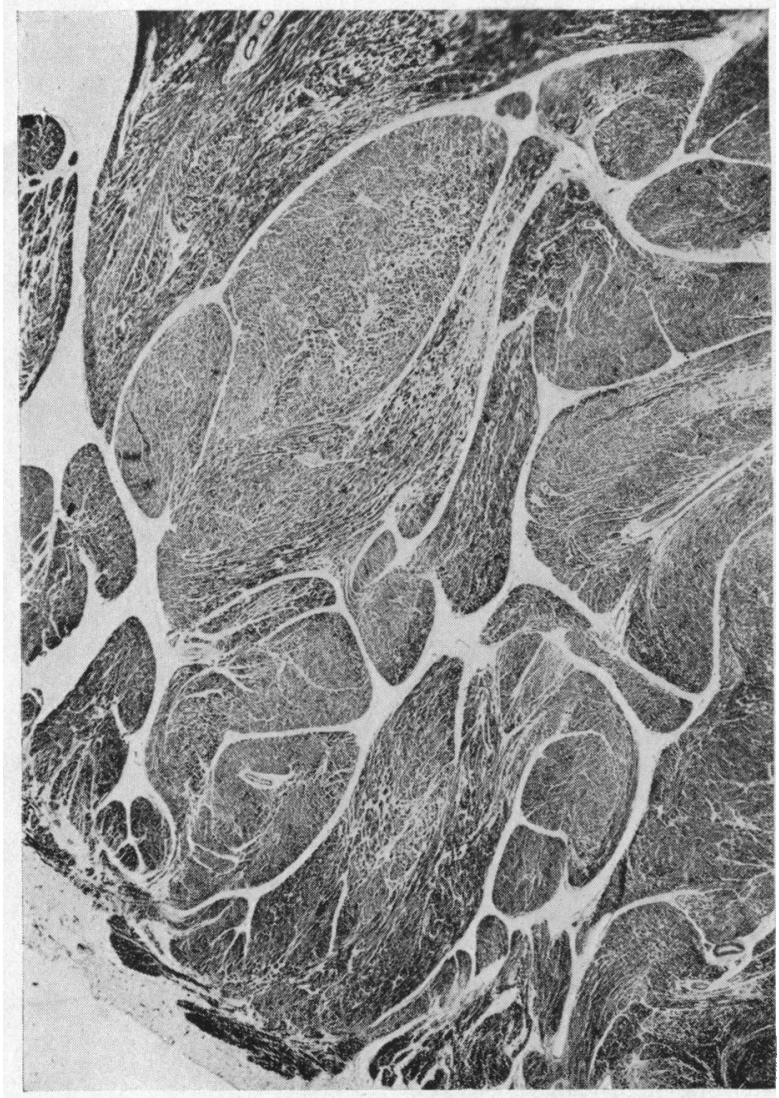

FIG. 5.-Case 3. Numerous large clefts between muscle bundles (H \& E × 7).

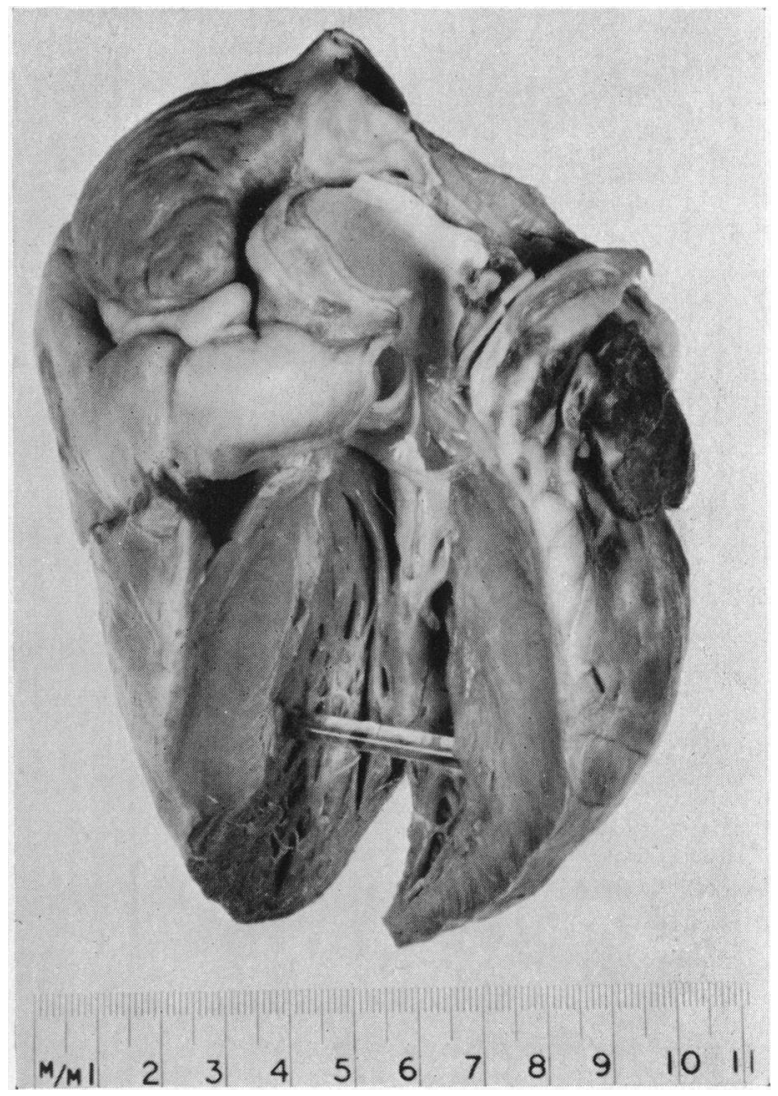

Fig. 6.-Case 4. Hypertrophy of the interventricular septum and anterior wall.

the little finger into the mitral valve and a hard mass, thought to be a calcified thrombus, was noted in the anterior ventricular wall. The mitral valve was split medially and laterally by means of a knife. Some six hours after the operation the blood pressure fell and despite all resuscitative measures death occurred in the early hours of the following morning.

The heart (Fig. 6) showed localized hypertrophy of the interventricular septum and anterior wall with distortion of the mitral valve into the shape of a fishes mouth (Fig. 7). While this distortion and bending of the valve undoubtedly caused narrowing there was no obvious thickening and microscopic section of the hypertrophied interventricular septum was identical with the previous cases.

Case 5. M. F. C., aged 21 years. While running to catch a bus in June, 1956, this young woman suddenly collapsed and was found to be dead on arrival at Wembley Hospital. Her cardiac history could be traced back to the age of eight when following scarlet fever, she had an illness diagnosed as rheumatism which confined her to bed for five months. Following this she attended a special school but at the age of 12 had a further illness with pain in the limbs and palpitation which led to her admittance to the Canadian Hospital, Taplow, where a diagnosis of congenital morbus cordis was made. At the age of 19 she attended Hammersmith Hospital complaining of palpitation and dyspnoa on exertion. She was found to have auricular fibrillation and an electrocardiogram showed right bundle-branch block. Eleven days after admission she reverted to normal rhythm, but two days later had a cerebral embolism. It was thought at this time that the diagnosis rested between Ebstein's syndrome and fibroelastosis. The girl's condition improved steadily and she remained well until the time of her sudden death. An electrocardiogram in September, 1954, showed right atrial hypertrophy and partial right bundle-branch block with questionable right ventricular hypertrophy. 


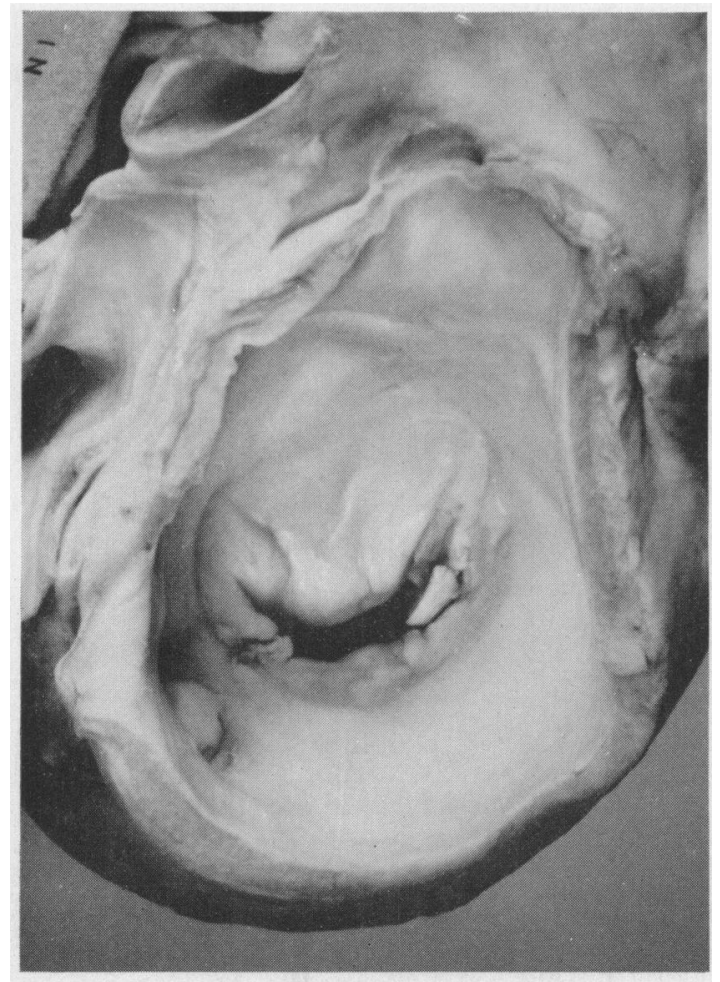

FIG. 7.-Case 4. Distortion of mitral valve.

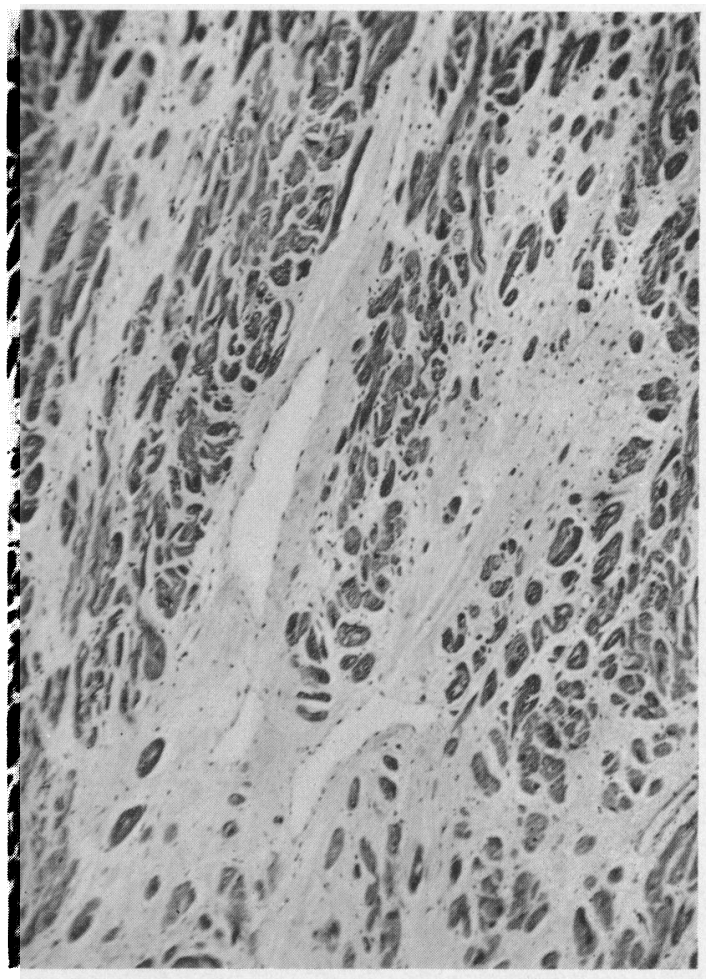

FIG. 8.-Case 5. Extensive fibrosis scattered through muscle bundles $(\mathrm{H} \& \mathrm{E} \times 80)$.

At autopsy she was found to be a well-nourished young woman with slight œdema of the ankles. The heart was almost globular in shape weighing $450 \mathrm{~g}$., and both ventricles being hypertrophied. The hypertrophy of the left ventricle was however completely asymmetrical affecting the interventricular septum and anterior wall. The posterior wall appeared to be rather thinner than normal. There was no valvular disease, nor endocarditis, and the coronary arteries and aorta were perfectly healthy. In other organs no congenital abnormalities were found, but an old area of softening was identified in the right temporal lobe of the brain. The liver showed cirrhotic changes indicative of chronic back pressure which may also have been responsible for the right ventricular hypertrophy.

Microscopical examination of the anterior wall of the heart showed bizarre arrangements of muscle bundles, with variation in the individual size of muscle fibres and their nuclei, and a considerable amount of fibrosis (Fig. 8). This fibrosis was found mainly in the centre of muscle bundles and was thought to be ischæmic in origin. A section of the posterior wall of the heart showed a normal arrangement of fibres of constant calibre.

The macroscopic picture of the heart in the three other cases was one of localized hypertrophy of the interventricular septum with a complete absence of vascular, coronary, or aortic disease.

Case 6. A. R., aged 33. This man was thought to have been rejected for military service because of a heart condition but had not consulted a doctor in the six years before his death. He collapsed suddenly on his way to work, and was dead on arrival at hospital. He was found to have a localized hypertrophy of the upper part of the interventricular septum.

Case 7. N. A., aged 28 years. The only history available in this case was one of insomnia for some weeks and he had not consulted a doctor during the 18 months before his death. He collapsed in the street and was dead on arrival at hospital. His heart weighed $390 \mathrm{~g}$. and showed localized hypertrophy of the interventricular septum encroaching on the anterior wall of the left ventricle. 
Case 8. J. B., aged 29 years. During a thunderstorm in September, 1951, this man was seen to fall from his pedal cycle and was dead when brought to hospital. The general practitioner was traced but had no record of any visit or consultation in the previous six years. Autopsy failed to reveal the slightest evidence of electric burns or serious injury resulting from the fall. The heart weighed $570 \mathrm{~g}$. and showed localized hypertrophy of the interventricular septum.

\section{Discussion}

Of the eight cases described, six occurred in men between the ages of 14 and 35 , one in a woman of 20 , and one in a woman of 44 . Four had had cardiac symptoms, two were discovered to have cardiac lesions on routine examination though symptom free, one had had slight insomnia, and the eighth was symptom free. In three cases palpitation was the most striking early symptom that led to medical examination; all three of these were found to have auricular fibrillation and were in some degree of heart failure, though not completely incapacitated. The young boy presented as an unexplained case of "blackouts" and this symptom was also exhibited by one woman.

In five cases hypertrophy of the right heart indicated some degree of long-standing back pressure, and in three cases there was evidence of chronic venous congestion in the liver. In no case was any other congenital abnormality found.

The macroscopic and microscopic pictures seen in all these cases is virtually the same, differing only in the degree of cleavage between coarse muscle bundles and to a lesser extent in the position of the localized hypertrophy. The overgrowth of muscle may impinge on the ventricular aspect of the mitral valve and lead to symptoms and signs of mitral stenosis so that it is not surprising therefore that Case 4 came to operation for mitral valvotomy.

It appears unlikely that this asymmetrical hypertrophy was traumatic or malignant in origin. The fibrosis evident in certain cases is ischæmic in type and the microscopical picture does not suggest a post-inflammatory condition, although in two cases a history suggestive of acute rheumatism was obtained. It must be admitted that the history available in other cases was so scanty as to be of little significance. The differential diagnosis appears to lie between a congenital and a developmental origin.

There are good reasons for believing that these lesions are in no way associated with congenital glycogenic degenerative tumours in that there was a complete absence of other congenital lesions, in particular cysts of the kidney and tuberous sclerosis, and no history of mental illness or epilepsy in any case: specific stains for the detection of glycogen were constantly negative.

\section{SUMMARY}

Eight cases of asymmetrical hypertrophy or muscular hamartoma of the heart are discussed. Seven of these caused sudden death in young adults. The pathological picture is one of bizarre and disorganized arrangement of muscle bundles associated with hypertrophy of individual muscle fibres and their nuclei.

\section{ADDENDUM}

On December 13, 1956, K. C., aged 16, a brother of Case No. 5, collapsed and died while riding his bicycle. No previous medical history was available. Post mortem he was found to be a well nourished and well developed young boy whose heart was virtually identical in appearance with that of his sister, showing a localized hypertrophy affecting the anterior wall and interventricular septum. By coincidence on the day of his death his younger sister attended the outpatient department of Hammersmith hospital and was found to have signs identical with her sister. This family will be the subject of another paper.

Dr. J. F. Goodwin, Mr. Donald Ross, Dr. J. Richardson, Dr. E. W. Paul, and Dr. E. D. Acheson have all allowed me the use of clinical notes and electrocardiograms. Dr. Aubrey Leatham has interpreted the latter for me. Miss J. Underhill and Miss S. Fry have photographed the specimens and Professor Crawford has provided the photomicrographs. To all these I am most grateful for help, advice, and encouragement. 


\section{REFERENCES}

Adams, R. D., Denny-Brown, D., and Pearson, C. M. (1953). Diseases of Muscle. Cassell, London. Batchelor, T. M., and Maun, M. E. (1945). Arch. Path., 39, 67.

Browne, G., and Gray, G. (1930). Lancet, 1, 915.

Eulinger, E. (1925). Virch Arch., 257, 719.

Friedberg, C. K. (1949). Diseases of the Heart. Philadelphia and London, 1003.

Hueper, W. C. (1955). Arch. Path., 19, 372. (1941). Amer. J. Path., 17, 121.

Mahaim, I. (1945). Les Tumeurs et les Polypes du Caur. Paris, Masson.

Saphir, O. (1953). In S. E. Gould's Pathology of the Heart. Charles C. Thomas, Illinois. 